\title{
Left ventricular diastolic dysfunction is linked to severity of obstructive sleep
} \section{apnoea}

\author{
J-P. Baguet*,\#, G. Barone-Rochette*,\#, P. Lévy ${ }^{\top,+}$, E. Vautrin*, H. Pierre*, \\ O. Ormezzano* ${ }^{\star \#}$ and J-L. Pépin ${ }^{\top,+}$
}

ABSTRACT: Obstructive sleep apnoea (OSA) has been linked to increased cardiovascular risk. The present study examined the relationships between respiratory parameters and left ventricular abnormalities in OSA.

150 newly diagnosed OSA patients without any known cardiovascular disease were included in the study (mean \pm SD age $49 \pm 11 \mathrm{yrs}$, body mass index $27.1 \pm 3.3 \mathrm{~kg} \cdot \mathrm{m}^{-2}$, respiratory disturbance index $41 \pm 18 \mathrm{~h}^{-1}$ ). Haemodynamic, biological, respiratory, cardiac and arterial parameters were assessed at inclusion.

$34(22.7 \%)$ patients had a grade 1 left ventricular diastolic dysfunction. Patients with an abnormal diastole were older $(\mathbf{p}<\mathbf{0 . 0 0 1})$ and $81 \%$ of them were hypertensive. The only respiratory parameter independently associated with the peak flow velocity in early diastole/peak flow velocity at atrial contraction ratio was mean nocturnal oxygen saturation. 17 (13\%) patients had left ventricular hypertrophy. A multivariate analysis showed that clinic systolic blood pressure and mean nocturnal oxygen saturation were independently associated with left ventricular hypertrophy. In a logistic regression model, age $\geqslant 58$ yrs (OR 3.29, 95\% Cl 1.78-5.64) and mean nocturnal oxygen saturation $<92 \%(\mathrm{OR} 2.76,95 \% \mathrm{Cl} 1.45-4.91)$ were associated with left ventricular diastolic dysfunction.

Our findings demonstrate that left ventricular diastolic dysfunction frequently occurs in patients with OSA and that it is related to the severity of oxygen desaturation.

KEYWORDS: Diastole, echocardiography, hypertension, left ventricular hypertrophy, sleep apnoea

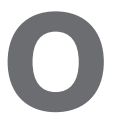

bstructive sleep apnoea (OSA) is a common but underestimated disease that has been related to increased cardiovascular risk [1]. Thus, hypertension, coronary artery disease (CAD), rhythm/ conduction problems and cerebrovascular diseases are often present in apnoeic patients, all the more so if the OSA is severe [2-5]. Morbidity and mortality connected to OSA are reduced by treatment with nasal continuous positive airway pressure (CPAP) [6]. The main mechanisms connected to OSA and involved in the genesis of cardiovascular diseases are sympathetic hyperactivity, endothelial dysfunction, systemic inflammation, insulin resistance, oxidative stress and coagulation anomalies [7-9].

Sleep apnoea is often found in patients with heart failure [10]. However, the combination of sleep apnoea and heart failure is different to the previously mentioned combinations (i.e. OSA with hypertension or CAD) as the majority of the sleep apnoea cases are central or mixed in heart failure patients. OSA can, nonetheless, lead to heart failure: systolic heart failure as after a myocardial infarction, or diastolic heart failure as is often the case in hypertensive patients. Almost half of heart failure patients have a preserved systolic function, i.e. a left ventricular (LV) ejection fraction $(\mathrm{LVEF}) \geqslant 45 \%$. Diastolic anomalies appear to be common in OSA, but the majority of studies in this area have been carried out on small patient populations [11-14]. LV hypertrophy $(\mathrm{LVH})$ often seems to be associated with this LV diastolic dysfunction [15].

The aim of this study was to determine the relationship between respiratory variables, and LV diastolic parameters and $\mathrm{LVH}$ in a large population of newly diagnosed OSA patients without any known cardiovascular disease.

\section{MATERIALS AND METHODS}

Study subjects

150 patients referred to the Grenoble University Hospital (Grenoble, France) sleep laboratory for
AFFILIATIONS

*Dept of Cardiology,

'Sleep Laboratory, Cardiopulmonary Functional Explorations Unit, University Hospital,

\#Bioclinic Radiopharmaceutics Laboratory, INSERM U877, and +INSERM ERI 17, HP2 Laboratory (Hypoxia, Pathophysiology), Joseph Fourier University, Grenoble, France.

CORRESPONDENCE

J-P. Baguet

Clinique de Cardiologie

CHU de Grenoble

BP 217

38043

Grenoble Cedex 09

France

E-mail: JPBaguet@chu-grenoble.fr

Received:

Oct 192009

Accepted after revision:

March 222010

First published online:

June 182010 
symptoms indicating OSA were included in November 2001July 2007. They were either recruited from the sleep laboratory, where they underwent full polysomnography, or from the ward sleep unit, where the diagnosis of OSA was confirmed by simplified polygraphy without electroencephalogram (EEG) recordings. None of the patients had any known cardiovascular disease and none of them were receiving any vasoactive treatment. We used the following exclusion criteria: diseases potentially affecting blood pressure (BP) regulation (e.g. Parkinson's disease, renal or cardiac transplantation, heart failure and diabetes mellitus); atrial fibrillation or frequent premature beats $\left(\geqslant 10\right.$ beats $\left.\cdot \mathrm{min}^{-1}\right)$, patients suffering from respiratory insufficiency and previous treatment of OSA. Ethical approval was obtained from the local ethics committee (Comité de Protection des Personnes, Grenoble, France) and all of the participants gave their informed consent.

\section{$B P$ and heart rate measurements}

Clinic BP was measured according to European Society of Hypertension (ESH)/European Society of Cardiology (ESC) guidelines [16]. The following parameters were assessed: systolic BP (SBP), diastolic BP (DBP) and pulse pressure (PP). Clinic hypertension was defined as a clinic SBP $\geqslant 140 \mathrm{mmHg}$ and/or a clinic DBP $\geqslant 90 \mathrm{mmHg}$. Clinic heart rate (HR) was measured by pulse palpation (30 s) in the supine position. Ambulatory BP monitoring (ABPM) was carried out with a Spacelabs 90207 device (Spacelabs International, Redmond, WA, USA). The measurements were made every 15 min over $24 \mathrm{~h}$. Daytime (07:00-22:00 h) hypertension was defined as daytime SBP $\geqslant 135 \mathrm{mmHg}$ and/or daytime DBP $\geqslant 85 \mathrm{mmHg}$, and nocturnal (22.00-07:00 h) hypertension as nocturnal SBP $\geqslant 120 \mathrm{mmHg}$ and/or nocturnal DBP $\geqslant 70 \mathrm{mmHg}$ [16]. Dipper pattern was defined by a nocturnal fall of $\mathrm{BP} \geqslant 10 \%$.

\section{Respiratory measurements}

Full polysomnography was performed in $108(72 \%)$ of the 150 patients. Continuous recordings were taken with electrode positions $\mathrm{C} 3 / \mathrm{A} 2-\mathrm{C} 4 / \mathrm{A} 1-\mathrm{Cz} / 01$ of the international 10-20 Electrode Placement System, eye movements, chin electromyogram and ECG modified V2 lead. Sleep was scored manually according to standard criteria [17]. Airflow was measured using nasal pressure associated with the sum of buccal and nasal thermistor signals. Respiratory efforts were monitored with abdominal and thoracic bands. An additional signal of respiratory effort (i.e. pulse transit time) was recorded concurrently. Pulse transit time allowed us to identify "autonomic activations" and, as a consequence, micro-arousals [18]. Thus, we were able to use the same rules and definition for hypopnoeas whatever the diagnosis technique used for diagnosing sleep apnoea. Arterial oxygen saturation $\left(\mathrm{Sp}_{\mathrm{p}}, \mathrm{O}_{2}\right)$ was measured using a pulse oximeter (Biox-Ohmeda $3700^{\circledR}$; Ohmeda, Liberty Corner, NJ, USA). The same variables were measured in the remaining 42 patients except for sleep variables, which were not recorded. An apnoea was defined as a complete cessation of airflow for $\geqslant 10 \mathrm{~s}$, and a hypopnoea as a $\geqslant 50 \%$ reduction in the nasal pressure signal or a $30-50 \%$ decrease, associated with either oxygen desaturation of $\geqslant 3 \%$ or an arousal (defined according to the Chicago report or by autonomic activations on pulse transit time), both lasting for $\geqslant 10 \mathrm{~s}[18,19]$. Apnoeas were classified as obstructive, central or mixed according to the presence or absence of respiratory efforts. The classification of hypopnoeas as obstructive or central was based upon the pulse transit time signal and the shape of the inspiratory part of the nasal pressure curve. A respiratory disturbance index (RDI) was calculated and defined as the number of apnoeas and hypopnoeas per hour of sleep (full polysomnography) or per hour of recording (polygraphy without EEG recording). In our study, diagnosis of OSA was retained if RDI $\geqslant 15 \mathrm{~h}^{-1}$.

\section{Echocardiography}

The echocardiogram was carried out using a HP Sonos 2500 (Hewlett Packard, Santa Clara, CA, USA) machine equipped with a $2.5-\mathrm{MHz}$ probe. The examination was performed in Mmode with two-dimensional (2D) guidance in the long axis of the left parasternal view. LV internal end-diastolic and endsystolic diameters, as well as interventricular septum and posterior wall thicknesses, were measured over five consecutive cycles. Systolic function was assessed by the LVEF according to the Teicholz formula. LV mass (LVM) was measured according to the Penn convention using the Devereux formula and was normalised for body surface area (BSA) and for height ${ }^{2.7}$ to derive the LVM index (LVMI) [20]. LVH was defined as an LVMI of $\geqslant 111 \mathrm{~g} \cdot \mathrm{m}^{-2}$ or $\geqslant 50 \mathrm{~g} \cdot \mathrm{m}^{-2}$ in males and of $\geqslant 106 \mathrm{~g} \cdot \mathrm{m}^{-2}$ or $\geqslant 47 \mathrm{~g} \cdot \mathrm{m}^{-2}$ in females [21]. Left atrial, end-systolic diameter was measured in M-mode in the parasternal long axis view. LV diastolic function was evaluated by transmitral Doppler using the pulsed Doppler technique with $2 \mathrm{D}$ guidance in apical four-chamber view [16, 22]. The following diastolic parameters were measured or calculated from at least three consecutive beats: E wave (peak flow velocity in early diastole); A wave (peak flow velocity at atrial contraction); and the E/A ratio. The mitral deceleration time (DT) and the Valsalva manoeuvre were used to distinguish the different filling patterns if necessary. A normal pattern was defined as E/A $>1$ and normal DT (160-240 ms); impaired relaxation was defined as E/A $<1$ and DT $>240 \mathrm{~ms}$; a pseudonormal pattern was defined as E/A 1-1.5, DT $>240 \mathrm{~ms}$ and reversal of the E/A ratio (to <1.0) by Valsalva manoeuvre; and a restrictive pattern was defined as $\mathrm{E} / \mathrm{A}>1.5$ and DT $<160 \mathrm{~ms}$. All echocardiograms were performed by the same experienced echocardiographer.

\section{Aortic pulse wave velocity}

To determine the carotid-to-femoral pulse wave velocity (PWV), two pulse transducers were fixed on the skin over the right common carotid and femoral arteries. The time delay was measured with a Complior ${ }^{\circledR}$ device (Artech Medical, Pantin, France), between the feet of simultaneously recorded pulse waves and averaged over 10 consecutive cycles. The carotid-femoral PWV was calculated as the distance between the arterial sites divided by the time delay.

\section{Biological parameters}

All the subjects had plasma measurements (enzymatic colorimetry) taken of total normal cholesterol, triglycerides, high-density lipoprotein cholesterol, low-density lipoprotein cholesterol (using the Friedwald formula), glucose and creatinine.

\section{Statistical analysis}

Statistical analyses were performed using SPSS software (SPSS Inc, Chicago, IL, USA). Normality of data distribution was assessed. 
Continuous data are presented as mean \pm SD. Relationships between the continuous variables were evaluated by Pearson's correlation analysis when data were normally distributed or by Spearman's correlation analysis when they were not normally distributed. Noncontinuous variables were compared using a Chi-squared test. Comparisons between groups for continuous variables were made using a paired t-test (or Mann-Whitney test when the data were not normally distributed). Multivariate analysis was performed by a stepwise regression. Variables included in our analysis were all the variables significantly $(p<0.05)$ associated with the explained variable using univariate analysis. Odds ratios (OR) were calculated using a logistic regression method to assess the significant association between an LV diastolic dysfunction on the one hand and parameters of OSA severity or other cardiovascular risk factors on the other hand. All ORs are presented with their 95\% confidence intervals (CI). Values of $\mathrm{p}<0.05$ were considered significant for all analyses.

\section{RESULTS}

\section{General data}

The anthropometric, biological and haemodynamic characteristics of the global cohort are presented in table 1. ABPM was valid for both daytime and nocturnal periods in $135(90 \%)$ of the 150 patients. $27(18 \%)$ subjects were obese, $102(76 \%)$ subjects were hypertensive (in clinic or in ABPM), 54 (36\%) subjects had clinic hypertension, 71 (53\%) subjects had daytime hypertension and 93 (69\%) subjects had nocturnal hypertension. The respiratory, cardiac and arterial characteristics of the global population are presented in table 2 .

\section{LV diastolic function}

$34(22.7 \%)$ out of 150 patients had an impaired LV relaxation. Patient characteristics, according to whether or not they had a diastolic dysfunction, are presented in tables 1 and 2. Patients with a diastolic dysfunction were older and had higher clinic $\mathrm{BP}$ and HR readings. 18 (53\%) subjects had clinic hypertension and $26(81 \%)$ subjects had abnormal ABPM. There was a trend towards greater LV diastolic dysfunction in subjects with hypertension than in normotensive subjects (33\% versus $23 \%$, respectively; $\mathrm{p}=0.11$ ).

Prevalence of nocturnal hypertension was higher in patients with impaired LV diastolic function than in those with normal LV function $(80 \%$ versus $67 \%$; $p=0.042)$. Half of the patients with impaired LV relaxation had a nondipper pattern $(42 \%$ of normal LV function subjects; $\mathrm{p}=0.71$ ).

TABLE 1 Anthropometric, biological and haemodynamic characteristics of the obstructive sleep apnoea patients

\begin{tabular}{|c|c|c|c|c|}
\hline & Total population & Normal diastole & Abnormal diastole & p-value \\
\hline Subjects $n$ & 150 & 116 & 34 & \\
\hline Age yrs & $49 \pm 11$ & $46 \pm 10$ & $57 \pm 9$ & $<0.001$ \\
\hline Males/females $n$ & $123 / 27$ & $97 / 19$ & $26 / 8$ & 0.34 \\
\hline $\mathrm{BMI} \mathrm{kg} \cdot \mathrm{m}^{-2}$ & $27.1 \pm 3.3$ & $27.0 \pm 3.2$ & $27.6 \pm 3.5$ & 0.36 \\
\hline Triglycerides $\mathrm{mmol} \cdot \mathrm{L}^{-1}$ & $1.37 \pm 1.11$ & $1.36 \pm 1.13$ & $1.44 \pm 1.02$ & 0.69 \\
\hline $\mathrm{HDL}$-cholesterol $\mathrm{mmol} \cdot \mathrm{L}^{-1}$ & $1.47 \pm 0.39$ & $1.47 \pm 0.39$ & $1.52 \pm 0.36$ & 0.19 \\
\hline $\mathrm{LDL}$-cholesterol $\mathrm{mmol} \cdot \mathrm{L}^{-1}$ & $3.30 \pm 0.98$ & $3.30 \pm 1.0$ & $3.50 \pm 0.93$ & 0.38 \\
\hline Glucose $\mathrm{mmol} \cdot \mathrm{L}^{-1}$ & $5.08 \pm 0.76$ & $5.06 \pm 0.68$ & $5.12 \pm 0.98$ & 0.30 \\
\hline Creatinine $\mu \mathrm{mol} \cdot \mathrm{L}^{-1}$ & $89.2 \pm 14.2$ & $89.3 \pm 14.4$ & $88.8 \pm 13.8$ & 0.86 \\
\hline Clinic HR beats $\cdot \min ^{-1}$ & $65 \pm 10$ & $64 \pm 10$ & $69 \pm 10$ & 0.012 \\
\hline Daytime SBP mmHg & $128 \pm 14$ & $127 \pm 14$ & $130 \pm 15$ & 0.22 \\
\hline Daytime DBP mmHg & $84 \pm 8$ & $84 \pm 8$ & $86 \pm 8$ & 0.16 \\
\hline Daytime PP mmHg & $44 \pm 9$ & $43 \pm 9$ & $44 \pm 10$ & 0.53 \\
\hline Daytime HR beats $\cdot \mathrm{min}^{-1}$ & $80 \pm 10$ & $80 \pm 10$ & $83 \pm 10$ & 0.14 \\
\hline Nocturnal SBP mmHg & $113 \pm 13$ & $112 \pm 13$ & $114 \pm 14$ & 0.38 \\
\hline Nocturnal DBP mmHg & $73 \pm 8$ & $72 \pm 8$ & $74 \pm 8$ & 0.11 \\
\hline Nocturnal PP mmHg & $40 \pm 9$ & $40 \pm 9$ & $40 \pm 10$ & 0.83 \\
\hline Nocturnal HR beats. $\min ^{-1}$ & $68 \pm 9$ & $67 \pm 9$ & $69 \pm 9$ & 0.13 \\
\hline Nondipper SBP \% & 39 & 38 & 41 & 0.78 \\
\hline Nondipper DBP \% & 27 & 24 & 37 & 0.14 \\
\hline
\end{tabular}

Data are presented as mean \pm SD, unless otherwise stated. BMI: body mass index; HDL: high-density lipoprotein; LDL: low-density lipoprotein; BP: blood pressure; HR heart rate; SBP: systolic BP; DBP: diastolic BP; PP: pulse pressure. Bold indicates statistically significant $\mathrm{p}$-values 


\begin{tabular}{|c|c|c|c|c|}
\hline \multicolumn{5}{|l|}{ Sleep respiratory variables } \\
\hline $\mathrm{RDI} \mathrm{h}^{-1}$ & $41 \pm 18$ & $40.2 \pm 18.0$ & $44.0 \pm 18.1$ & 0.28 \\
\hline Micro-arousal index $\mathrm{h}^{-1}$ & $37.2 \pm 14.7$ & $37.2 \pm 14.7$ & $37 \pm 14.9$ & 0.94 \\
\hline Minimal nocturnal $\mathrm{Sp}, \mathrm{O}_{2} \%$ & $83.7 \pm 6.7$ & $84.2 \pm 6.6$ & $82.1 \pm 7.2$ & 0.11 \\
\hline Recording time spent at a $\mathrm{Sp}, \mathrm{O}_{2}<90 \% \%$ & $7.3 \pm 15.8$ & $6.1 \pm 14.9$ & $11.4 \pm 18.2$ & 0.13 \\
\hline \multicolumn{5}{|l|}{ Cardiac parameters } \\
\hline IVS thickness mm & $8.5 \pm 1.2$ & $8.4 \pm 1.2$ & $8.9 \pm 1.4$ & 0.06 \\
\hline LVPW thickness mm & $9.0 \pm 1.2$ & $8.9 \pm 1.1$ & $9.4 \pm 1.3$ & 0.055 \\
\hline LVD mm & $48.7 \pm 4.8$ & $48.7 \pm 4.8$ & $48.4 \pm 4.9$ & 0.75 \\
\hline LVMI-height $^{2.7} \mathrm{~g} \cdot \mathrm{m}^{-1}$ & $39.1 \pm 8.4$ & $38.2 \pm 8.3$ & $42.5 \pm 8.3$ & 0.016 \\
\hline LVH-BSA \% & 7.7 & 5.3 & 16.1 & 0.13 \\
\hline LVH-height $2.7 \%$ & 11.4 & 8.6 & 21.4 & 0.13 \\
\hline Left atrial diameter $\mathrm{mm}$ & $35.7 \pm 4.7$ & $35.7 \pm 4.6$ & $35.9 \pm 4.9$ & 0.82 \\
\hline E wave $\mathrm{m} \cdot \mathrm{s}^{-1}$ & $68 \pm 16$ & $50.4 \pm 12.5$ & $68.3 \pm 13.2$ & $<0.001$ \\
\hline A wave $\mathrm{m} \cdot \mathrm{s}^{-1}$ & $54 \pm 15$ & $71.3 \pm 14.2$ & $56.1 \pm 14.9$ & $<0.001$ \\
\hline E/A ratio & $1.33 \pm 0.42$ & $1.46 \pm 0.33$ & $0.86 \pm 0.33$ & $<0.001$ \\
\hline Abnormal diastole \% & 23 & 0 & 100 & $<0.001$ \\
\hline \multicolumn{5}{|l|}{ Arterial parameter } \\
\hline Aortic $\mathrm{PWV}^{\#} \mathrm{~m} \cdot \mathrm{s}^{-1}$ & $9.0 \pm 1.4$ & $8.79 \pm 1.29$ & $9.85 \pm 1.68$ & 0.001 \\
\hline
\end{tabular}

Data are presented as mean $\pm \mathrm{SD}$, unless otherwise stated. RDI: respiratory disturbance index; $\mathrm{Sp}, \mathrm{O}_{2}$ : arterial oxygen saturation measured by pulse oximetry; IVS: interventricular septum; LVPW: left ventricular (LV) posterior wall; LVD: LV internal end-diastolic; LVEF: LV ejection fraction; LVM: LV mass; LVMI: LVM index; BSA: body surface area; LVH: LV hypertrophy; E: peak flow velocity in early diastole; A: peak flow velocity in atrial contraction; PWV: pulse wave velocity. ${ }^{*}: n=124$. Bold indicates statistically significant $\mathrm{p}$-values.

If there was diastolic dysfunction, LVMI-height ${ }^{2.7}$ and PWV were higher and mean nocturnal $\mathrm{Sp}_{\mathrm{p}} \mathrm{O}_{2}$ was lower (fig. 1). In the total population, a correlation analysis showed that $\mathrm{E} / \mathrm{A}$ was significantly related to age $(\mathrm{r}=-0.52 ; \mathrm{p}<0.001)$, clinic DBP $(\mathrm{r}=-0.27 ; \mathrm{p}=0.001)$ and SBP $(\mathrm{r}=-0.26 ; \mathrm{p}=0.002), \quad \mathrm{PWV}$ $(\mathrm{r}=-0.24 ; \mathrm{p}=0.007)$, RDI $(\mathrm{r}=-0.18 ; \mathrm{p}=0.027)$ and mean nocturnal $\mathrm{Sp}_{\mathrm{p}} \mathrm{O}_{2}(\mathrm{r}=0.41 ; \mathrm{p}<0.001$; fig. 2$)$ but not to LVMIheight $^{2.7}$. In the subgroup of normotensive subjects, E/A ratio was significantly correlated to age $(r=-0.56 ; p<0.001)$, mean nocturnal $S_{\mathrm{p}, \mathrm{O}_{2}}(\mathrm{r}=0.47 ; \mathrm{p}<0.001)$ and clinic DBP $(\mathrm{r}=-0.21$; $\mathrm{p}=0.038$ ).

A stepwise regression analysis showed that, in the whole population, the only respiratory parameter independently associated with $\mathrm{E} / \mathrm{A}$ was mean nocturnal $\mathrm{Sp}_{\mathrm{P}, \mathrm{O}_{2}} \quad(\beta=0.29$; $\mathrm{p}=0.001)$. A logistic regression model showed that age $\geqslant 58$ yrs (OR 3.29, 95\% CI 1.78-5.64) and a mean nocturnal ${\mathrm{Sp}, \mathrm{O}_{2}}_{2}<92 \%$ (OR 2.76, 95\% CI 1.45-4.91) were associated with LV diastolic dysfunction.

\section{LV mass}

Cardiac ultrasound was valid for LV dimensions in $132(88 \%)$ out of 150 patients. All the patients had a LVEF $\geqslant 45 \%$ and 27 $(18 \%)$ subjects had a left atrial dilation (diameter $\geqslant 40 \mathrm{~mm}$ ). Patients with a LVH-height ${ }^{2.7}(\mathrm{n}=17,13 \%)$ had a higher $24-\mathrm{h}$
SBP (134 \pm 13 versus $122 \pm 13 ; \mathrm{p}=0.003)$, a lower mean nocturnal $\mathrm{Sp}_{\mathrm{p}, \mathrm{O}_{2}}(91.9 \pm 3.1$ versus $93.7 \pm 1.6 ; \mathrm{p}<0.001)$ and a higher $\mathrm{RDI}$ ( $47.0 \pm 17.1$ versus $37.9 \pm 15.3 ; \mathrm{p}=0.033)$. LVMI-BSA and LVMIheight ${ }^{2.7}$ were correlated to the BP parameters $(r=0.41$, $\mathrm{p}<0.001$ for LVMI-height ${ }^{2.7}$ and nocturnal PP). Among patients with LVH, 91\% had nocturnal hypertension $(67 \%$ in subjects without $\mathrm{LVH} ; \mathrm{p}=0.088$ ) and $46 \%$ were nondippers ( $43 \%$ in absence of LVH; $p=0.55$ ). The LVMI-height ${ }^{2.7}$ was similar in dipper and nondipper groups $(38.0 \pm 8.5$ versus $39.3 \pm 7.7 \mathrm{~g} \cdot \mathrm{m}^{-1}$, respectively; $\mathrm{p}=0.39$ ). There was a significant correlation between LVMI-height ${ }^{2.7}$ on the one hand and mean nocturnal $S_{\mathrm{p}, \mathrm{O}_{2}}(\mathrm{r}=-0.30 ; \mathrm{p}=0.001$; fig. 2$)$, minimal nocturnal $\mathrm{Sp}_{\mathrm{O}} \mathrm{O}_{2}(\mathrm{r}=-0.23 ; \mathrm{p}=0.01)$, RDI $(\mathrm{r}=0.21, \mathrm{p}=0.015)$ and age $(\mathrm{r}=0.18, \mathrm{p}=0.034)$ on the other hand. A multivariate analysis revealed that clinic SBP $(\beta=0.30 ; p=0.001)$ and mean nocturnal $\mathrm{Sp}_{\mathrm{O}} \mathrm{O}_{2}(\beta=-0.26 ; \mathrm{p}=0.003)$ were independently associated with LVMI-height ${ }^{2.7}$.

\section{DISCUSSION}

Unlike most of the studies previously published in the field, our results came from a large cohort of newly diagnosed OSA patients, who were essentially nonobese, not known to be hypertensive before inclusion in the study, not receiving any vasoactive medications and in whom $24-\mathrm{h}$ ABPM had been 


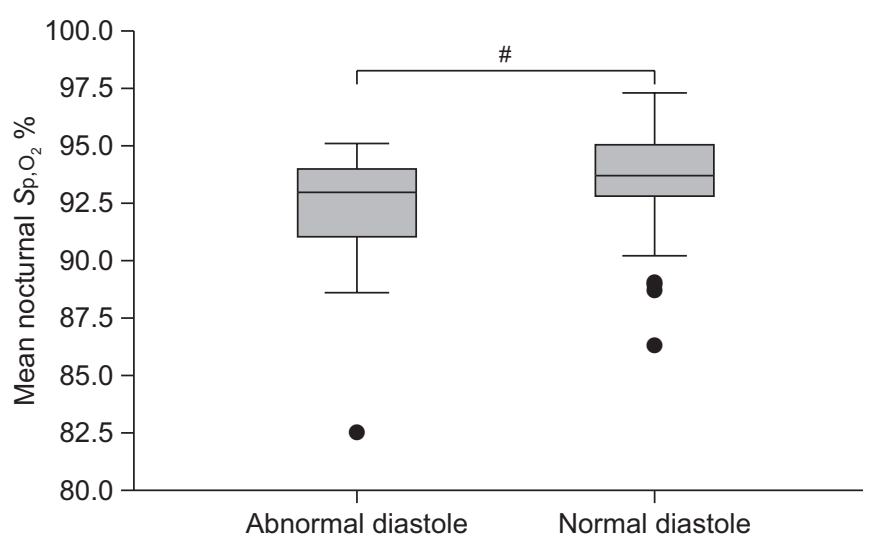

FIGURE 1. Mean nocturnal arterial oxygen saturation measured by pulse oximetry $\left(\mathrm{Sp}, \mathrm{O}_{2}\right)$ was significantly lower in the abnormal diastole group $(n=34)$ compared with the normal diastole group $(n=116)$. Boxes represent values within the interquartile range; whiskers represent the data range; and the line across the boxes represents median values. ${ }^{*}: p=0.002$.

performed systematically. Our study is unique, not only because main confounders were discarded, but also because a complete cardiovascular phenotype was obtained in the full set of patients.

The main results of our study are as follows: 1) nearly one quarter of OSA patients had an LV diastolic dysfunction; 2) the more severe was OSA, the higher was the prevalence of LV diastolic dysfunction; 3) the only respiratory parameter independently associated with $\mathrm{E} / \mathrm{A}$ was mean nocturnal $\mathrm{Sp}, \mathrm{O}_{2}$; and 4) clinic SBP and mean nocturnal $\mathrm{Sp}, \mathrm{O}_{2}$ were the only variables independently associated with LVMI-height ${ }^{2.7}$.

\section{LV diastolic dysfunction}

As we previously published in a subset of the same cohort, the prevalence of hypertension evidenced by ABPM is very high, even in OSA subjects supposedly free of cardiovascular consequences [23]. Morbidity and mortality in heart failure patients with preserved LV systolic function (i.e. diastolic dysfunction) is high. Hypertension, diabetes mellitus, LVH, myocardial ischaemia and LV systolic dysfunction are frequently associated with diastolic dysfunction. OSA is frequent in heart failure patients [24]. Conversely, the presence of OSA led to an increase in the likelihood of having heart failure, independently of other known risk factors [25].

The methods used to analyse LV diastole vary from one published study to another. We have chosen a simple and validated index, E/A, combined with a measurement of the DT of the $\mathrm{E}$ wave and with the performance of a Valsalva manoeuvre. We found a high prevalence $(23 \%)$ of LV diastolic dysfunction (impaired relaxation pattern). Therefore, this shows that, in newly diagnosed OSA patients, there is essentially an LV relaxation anomaly. In our study, patients with an LV diastolic dysfunction were older with a higher clinic BP, LVMI and aortic stiffness. As in our study, ARIAS et al. [12], found a high prevalence (56\%) of abnormal LV filling patterns in 27 OSA patients, with a majority of subjects suffering from an impaired relaxation pattern. On the contrary, in 353 apnoeic patients, NIROUMAND et al. [26] concluded that OSA is not independently associated with impaired LV
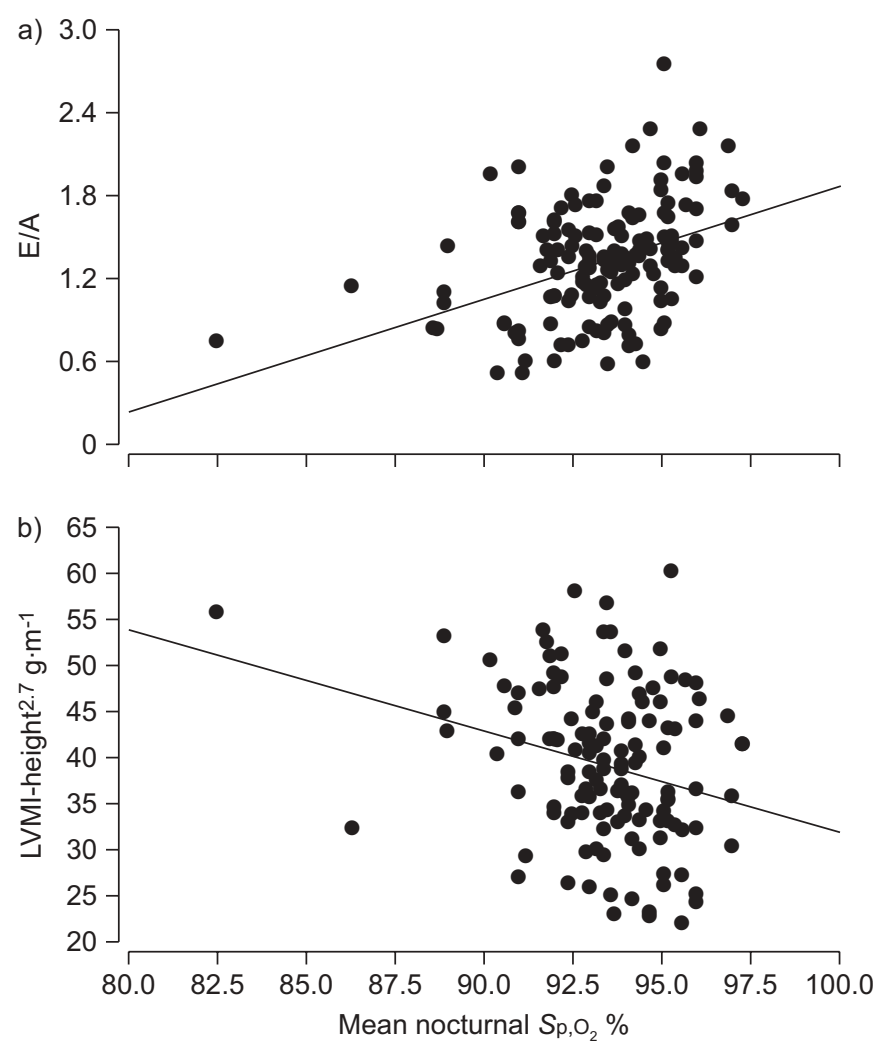

FIGURE 2. a) Peak flow velocity in early diastole/peak flow velocity at atria contraction ( $E / A) \quad(r=0.41 ; p<0.001)$ and $b)$ left ventricular mass index (LVMI)height $^{2.7}(r=-0.30 ; p=0.001)$ were correlated to mean nocturnal arterial oxygen saturation measured by pulse oximetry $\left(\mathrm{Sp}, \mathrm{O}_{2}\right)$

diastolic function evaluated by E/A. However, in this last study, patients were obese and $21 \%$ were known to be hypertensive upon inclusion. In the study of ARIAS et al. [12], the RDI was the only predictive factor of $\mathrm{LV}$ diastolic dysfunction. Importantly, more severe OSA is associated with a higher degree of LV diastolic dysfunction [11, 27]. Using Doppler tissue imaging, several authors found an independent relationship between OSA severity and LV diastolic parameters (mitral annulus velocities) [14]. Our study, which was performed on a larger cohort of OSA patients than most of the studies cited here, demonstrates that only mean nocturnal $\mathrm{Sp}_{\mathrm{p}} \mathrm{O}_{2}$ is independently linked to E/A. Moreover, we found that a mean nocturnal $S \mathrm{p}, \mathrm{O}_{2}$ of $<92 \%$ led to a 2.76 -fold increase in the likelihood of suffering from an LV diastolic dysfunction. As a single value, minimal nocturnal $S p, \mathrm{O}_{2}$ does not reflect the overall nocturnal hypoxaemia and is frequently, as in our study for the LV diastolic function, unrelated to cardiovascular or metabolic consequences. Time spent at a $\mathrm{Sp}, \mathrm{O}_{2}<90 \%$ is an interesting indicator of the amount of desaturations. However as our patients were lean and exhibited moderate-to-severe OSA, a significant proportion of them (24\%) had $0 \%$ of time spent at $\mathrm{Sp}, \mathrm{O}_{2}<90 \%$. This measure was not normally distributed and not sensitive enough to demonstrate a relationship with $\mathrm{LV}$ diastolic dysfunction.

How can we explain this relationship between OSA and LV diastolic function? First, the BP increase during OSA leads to a pressure overload inside the $\mathrm{LV}$, which in turn causes filling impairment. 
Secondly, during apnoeas, there is an increase in sympathetic nervous system activity, which can also cause LV pressure overload [7]. Moreover, after each micro-arousal, there is an increase in the pulmonary capillary wedge pressure, which can lead to a concomitant reduction in LV compliance. Another mechanism that can promote LV diastolic dysfunction is the greater frequency of episodes of negative intrathoracic pressure in apnoeic subjects. This pressure modification can lead to an increase in LV wall tension and LV afterload, culminating in a reduction in stroke volume during apnoeas. The overdistention of the right ventricle during OSA can also reduce LV filling. Increased arterial stiffness may also lead to LV diastolic dysfunction through an increase in LV systolic overload which can cause LVH and consequently changes to LV filling. Thus, some authors found a relationship between aortic stiffness and LV diastolic anomalies [13, 28]. This is partly confirmed by our data. Indeed, the significant negative relationship between E/A and PWV disappears when age and $\mathrm{BP}$ are taken into account. Another mechanism is a possible release of mediators affecting the left ventricle due to the hypoxia-reoxygenation sequences. Indeed, in our study, the only parameter significantly associated with E/A was mean nocturnal $\mathrm{Sp}, \mathrm{O}_{2}$.

\section{LV hypertrophy}

Hypertension is the most common risk factor for $\mathrm{LVH}$ and heart failure in longitudinal studies. LVH is a major and independent risk factor for cardiovascular events. In hypertensive patients, LVM has been find to be higher in nondipperpattern subjects [29]. In our study, we did not found a similar result, but $91 \%$ of the OSA patients with LVH had nocturnal hypertension (versus $67 \%$ in subjects without LVH). For these haemodynamic reasons, apnoeic patients are at greater risk of developing LVH.

The numerous episodes of hypoxaemia recorded during apnoeas also seem to play a role in the constitution of LVH. Another mechanism leading to LVH is the increased sympathetic activity observed during OSA. However, study results do not always point in the same direction. For some authors, $\mathrm{LVH}$ is more prevalent in OSA patients [30,31]. In our study, we found a lower prevalence of LVH than that observed in these previous studies. This can be explained in part by the characteristics of our population (i.e. newly diagnosed OSA patients without any known cardiovascular disease). NIROUMAND et al. [26] concluded that OSA is not associated with increased LVM independently of obesity, hypertension or advancing age.

It is not always possible to measure LVM in apnoeic patients, as they are often overweight. Consequently, indexation of LVM to height ${ }^{2.7}$ would seem to be more appropriate in apnoeic patients than indexation to BSA [21]. In our study, LVMI was significantly higher when there was an LV diastolic dysfunction when normalisation for height ${ }^{2.7}$ was used. In line with other authors, we found a positive and independent relationship between the severity of OSA, estimated by mean nocturnal $S \mathrm{p}, \mathrm{O}_{2}$, and LVM [11, 14, 32]. Conversely, HEDNER et al. [30] did not note such a link. However, in their study, 17 out of 31 hypertensive patients were using pharmacological antihypertensive treatment.

\section{Conclusion}

LV diastolic dysfunction and LVH appear early in OSA patients, independently of their BP levels. This may partly explain the high prevalence of cardiovascular events observed in this specific population. We found that only mean nocturnal $\mathrm{Sp}_{\mathrm{O}} \mathrm{O}_{2}$ is associated with $\mathrm{LV}$ diastolic dysfunction and $\mathrm{LVH}$. Given the cardiovascular risk associated with these cardiac anomalies, carrying out a cardiac Doppler ultrasound could be useful in the initial assessment of patients suffering from OSA.

\section{Perspectives}

Interventional studies are desirable in this field. The randomised clinical trial in a small number of patients of ARIAS et al. [12] suggested that effective CPAP application led to LV diastolic function improvement. In the current cohort, there is an on going study investigating CPAP efficacy on LV diastolic function.

\section{Study limitations}

The mitral flow velocity pattern has a limited ability to differentiate normal versus abnormal LV diastolic function due to the effects of loading conditions, age and HR. However, the parameters used in the present study have been validated by numerous studies and recommended in the recent ESH-ESC guidelines on hypertension [16].

We have used simplified techniques for assessing OSA diagnosis and severity in a subgroup of the included patients. However, diastolic dysfunction in our study mainly correlated with $\mathrm{Sp}_{\mathrm{p}, \mathrm{O}_{2}}$ parameters which are properly assessed by simplified sleep studies.

We acknowledge that the absence of a control group could be considered as an important study limitation. However, this lack of control group does not preclude the demonstration of an independent relationship between LV diastolic function and LVM on the one hand and mean nocturnal $S \mathrm{p}, \mathrm{O}_{2}$ on the other hand.

\section{SUPPORT STATEMENT}

This study was funded by the DRRC of Grenoble University Hospital (Grenoble, France) and by the Comite National des Maladies Respiratoires (National Committee for Respiratory Illnesses; Comares, France). These funding sources had no involvement in the collection, analysis, interpretation of data, writing the report or in the decision to submit the paper for publication.

\section{CLINICAL TRIAL}

This study is registered at ClinicalTrials.gov with clinical trial identifier number NCT00764218.

\section{STATEMENT OF INTEREST}

None declared.

\section{REFERENCES}

1 Young T, Peppard P, Gottlieb D. The epidemiology of obstructive sleep apnoea: a population health perspective. Am J Respir Crit Care Med 2002; 165: 1217-1239.

2 Peker Y, Hedner J, Kraiczi H, et al. Respiratory disturbance index. An independent predictor of mortality in coronary artery disease. Am J Respir Crit Care Med 2000; 162: 81-86.

3 Peppard PE, Young T, Palta M, et al. Prospective study of the association between sleep-disordered breathing and hypertension. N Engl J Med 2000; 342: 1378-1384. 
4 Lattimore JD, Celermajer DS, Wilcox I. Obstructive sleep apnea and cardiovascular disease. J Am Coll Cardiol 2003; 41: 1429-1437.

5 Baguet JP, Hammer L, Lévy P, et al. Night-time and diastolic hypertension are common and underestimated conditions in newly diagnosed apnoeic patients. J Hypertens 2005; 23: 521-527.

6 Marin JM, Carrizo SJ, Vicente E, et al. Long-term cardiovascular outcomes in males with obstructive sleep apnoea-hypopnoea with or without treatment with continuous positive airway pressure: an observational study. Lancet 2005; 365: 1046-1053.

7 Somers VK, Dyken ME, Clary MP, et al. Sympathetic neural mechanisms in obstructive sleep apnea. J Clin Invest 1995; 96: 1897-1904.

8 Coughlin SR, Mawdsley L, Mugarza JA, et al. Obstructive sleep apnoea is independently associated with an increased prevalence of metabolic syndrome. Eur Heart J 2004; 25: 735-741.

9 Robinson GV, Pepperell JC, Segal HC, et al. Circulating cardiovascular risk factors in obstructive sleep apnoea: data from randomised controlled trials. Thorax 2004; 59: 777-782.

10 Javaheri S, Parker TJ, Liming JD, et al. Sleep apnea in 81 ambulatory male patients with stable heart failure. Types and their prevalences, consequences, and presentations. Circulation 1998; 97: 2154-2159.

11 Kraiczi H, Caidahl K, Samuelsson A, et al. Impairment of vascular endothelial function and left ventricular filling. Association with the severity of apnea-induced hypoxemia during sleep. Chest 2001; 119: 1085-1091.

12 Arias MA, Garcia-Rio F, Alonso-Fernandez A, et al. Obstructive sleep apnea syndrome affects left ventricular diastolic function. Effects of nasal continuous positive airway pressure. Circulation 2005; 112: 375-383.

13 Kasikcioglu HA, Karasulu L, Durgun E, et al. Aortic elastic properties and left ventricular diastolic dysfunction in patients with obstructive sleep apnea. Heart Vess 2005; 20: 239-244.

14 Shivalkar B, van de Heyning C, Kerremans M, et al. Obstructive sleep apnea syndrome. More insights on structural and functional cardiac alterations, and the effects of treatment with continuous positive airway pressure. J Am Coll Cardiol 2006; 47: 1433-1439.

15 Lorell BH, Carabello BA. Left ventricular hypertrophy. Pathogenesis, detection, and prognosis. Circulation 2000; 102 470-479.

16 Mancia G, De Bacher G, Domoniczak A, et al. 2007 guidelines for the management of arterial hypertension. The task force for the management of arterial hypertension of the European Society of Hypertension (ESH) and of European Society of Cardiology (ESC). J Hypertens 2007; 25: 1105-1187.

17 Rechtschaffen A, Kales A. A manual of standardized terminology, techniques and scoring system for sleep stages of human subjects. Washington, National Institutes of Health, 1968.
18 Argod J, Pépin JL, Smith RP, et al. Comparison of esophageal pressure with pulse transit time as a measure of respiratory effort for scoring obstructive nonapneic respiratory events. Am J Respir Crit Care Med 2000; 162: 87-93.

19 The Report of an American Academy of Sleep Medicine Task Force. Sleep-related breathing disorders in adults: recommendations for syndrome definition and measurement techniques in clinical research. Sleep 1999; 22: 667-689.

20 Devereux RB, Reichek N. Echocardiographic determination of left ventricular mass in man. Circulation 1977; 55: 613-618.

21 De Simone G, Devereux RB, Roman MJ, et al. Relation of obesity and gender to left ventricular hypertrophy in normotensive and hypertensive adults. Hypertension 1994; 23: 600-606.

22 Oh JK, Appleton CP, Hatle LK, et al. The noninvasive assessment of left ventricular diastolic function with two-dimensional and Doppler echocardiography. J Am Soc Echocardiogr 1997; 10: 246-270.

23 Baguet JP, Lévy P, Barone-Rochette G, et al. Masked hypertension in obstructive sleep apnea syndrome. J Hypertens 2008; 26: 885-892.

24 Sin DD, Fitzgerald F, Parker JD, et al. Risk factors for central and obstructive sleep apnea in 450 males and females with congestive heart failure. Am J Respir Crit Care Med 1999; 160: 1101-1106.

25 Shahar E, Whitney CW, Redline S, et al. Sleep-disordered breathing and cardiovascular disease: cross-sectional results of the Sleep Heart Health Study. Am J Respir Crit Care Med 2001; 163: 19-25.

26 Niroumand M, Kuperstein R, Sasson Z, et al. Impact of obstructive sleep apnea on left ventricular mass and diastolic function. Am J Respir Crit Care Med 2001; 163: 1632-1636.

27 Tomiyama H, Takata Y, Shiina K, et al. Concomitant existence and interaction of cardiovascular abnormalities in obstructive sleep apnea subjects with normal clinic blood pressure. Hypertens Res 2009; 32: 201-206.

28 Drager LF, Bortolotto LA, Figueiredo AC, et al. Obstructive sleep apnea, hypertension, and their interaction on arterial stiffness and heart remodelling. Chest 2007; 131: 1379-1386.

29 Verdecchia P, Schillaci G, Guerrieri M, et al. Circadian blood pressure changes and left ventricular hypertrophy in essential hypertension. Circulation 1990; 81: 528-536.

30 Hedner J, Ejnell H, Caidahl K. Left ventricular hypertrophy independent of hypertension in patients with obstructive sleep apnoea. J Hypertens 1990; 8: 941-946.

31 Cloward TV, Walker JM, Farney RJ, et al. Left ventricular hypertrophy is a common echocardiographic abnormality in severe obstructive sleep apnea and reverses with nasal continuous positive airway pressure. Chest 2003; 124: 594-601.

32 Dursunoglu D, Dursunoglu N, Evrengul H, et al. Impact of obstructive sleep apnea on left ventricular mass and global function. Eur Respir J 2005; 26: 283-288. 